\title{
Scanning Electron Microscopy and Kinetic Studies of Ketene-Acetylated Wood/Cellulose High-Density Polyethylene Blends
}

\author{
Yakubu Azeh, ${ }^{1}$ Gabriel Ademola Olatunji, ${ }^{2}$ and Paul Andrew Mamza ${ }^{1}$ \\ ${ }^{1}$ Department of Chemistry, Ibrahim Badamasi Babangida University, Lapai, Nigeria \\ ${ }^{2}$ Department of Chemistry, University of Ilorin, Ilorin, Nigeria \\ Correspondence should be addressed to Yakubu Azeh, azehyakubu@yahoo.com
}

Received 16 August 2012; Revised 17 November 2012; Accepted 18 November 2012

Academic Editor: R. J. Linhardt

Copyright (C) 2012 Yakubu Azeh et al. This is an open access article distributed under the Creative Commons Attribution License, which permits unrestricted use, distribution, and reproduction in any medium, provided the original work is properly cited.

\begin{abstract}
Acetylated cellulose and wood cellulose as well as untreated cellulose polyethylene blends were subjected to kinetic studies using water, $0.5 \mathrm{M} \mathrm{NaOH}$, and $0.5 \mathrm{M} \mathrm{HCl}$ solutions in order to investigate their absorbent properties at $0.5 / 1.0$ cellulose/wood cellulose/polyethylene matrix. The results of the absorption studies showed that the untreated cellulose and wood cellulose blends absorbed water and the acid and alkali solutions higher than the treated samples, which showed a reduction in acid, alkali, and water uptake. In this work, the effects of acetylation on the morphological studies of the polyethylene blends were obvious. The presence of acetyl groups improved the interfacial bonding between the polymer matrix and cellulose as well as the wood cellulose fibers, as evidenced by scanning electron microscopy (SEM).
\end{abstract}

\section{Introduction}

A better understanding of the chemical composition and surface properties/chemistry of natural fibers is necessary for ease of developing natural fiber-reinforced composites/blends. Cellulose is the most abundant biopolymer in nature and its biosynthesis, chemistry, and ultrastructure remain an active field of study. Over the past decades, the interest in sustainability and green chemistry has led to a renewed interest in novel cellulosic materials and composites derived from a variety of cellulosic materials [1]. Cellulose is a homopolysaccharide which is a highly stable chain composed of 12,000 of $\beta$-D-glucopyranose monomeric units linked together by covalently bonded $\beta 1 \rightarrow 4$-glycosidic linkages in long chains, resulting in bundles known as microfibrils that can be easily cleaved by mineral acids $[2,3]$. Each $\beta$-D-glucopyranose unit is oriented at an angle of $180^{\circ}$ from the succeeding glucose unit [2]. Native cellulose is composed of amorphous and crystalline domains. The crystalline domains are highly ordered and much more stable to acid hydrolysis compared to their amorphous counterparts [3]. Native cellulose based materials (wood, hemp, cotton, linen, etc.) have been used as construction materials $[4,5]$. Cellulose is the basic structural component of all plant fibers, the most important organic biopolymer produced by plants and the most abundant renewable polymer resource available today worldwide [6]. Cellulose is a polymer raw material which has served mankind as a construction material, mainly in the form of solid wood and textile fibers, such as cotton or flax, or in the form of paper and board for many decades. On the other hand, cellulose is a versatile starting material for chemical conversions aiming at the production of value-added products such as cellulose-based surgical threads and films as well as a variety of stable cellulose derivatives used in many areas of industry and domestic life $[3,7]$. Cellulose belongs to the class of organic compounds known as carbohydrates and cotton is known to be the purest form of cellulose [8]. Cellulose is a chain polymer and forms microfibrils, which are embedded in a matrix, composed of amorphous hemicelluloses bonded together in relatively short, branching chains and are very hydrophilic $[3,9]$. It has been shown that the crystalline domain of cellulose may contain several types of lattices (I $\beta$, II, III, and IV), depending on the origin of cellulose as well as 
the chemical treatments used during the processing of the source materials [10]. Cellulose has no taste, is odourless, hydrophilic, is insoluble in water and most organic solvents, is stereogenic, and is highly biodegradable. It can be broken down into its monomer glucose units when treated with certain enzymes or concentrated acids at high temperature. Cellulose requires a temperature of $320^{\circ} \mathrm{C}$ and pressure of $25 \mathrm{MPa}$ to become amorphous in water [11]. The strong hydrogen bonding network within the cellulose molecules greatly affects the properties of cellulose. For instance, properties such as swelling, absorption, and optical behavior are influenced by the hydrogen bonding. Swelling of cellulose is because the natural fiber exhibits a high hydrophilicity due to attractions and interaction between the hydroxyl groups of fiber components and water molecules which originate from the noncrystalline region and extende to the crystalline region $[11,12]$. The swelling of cellulose is to a certain extent reversible when the surrounding humidity level is increased or decreased. Water exchange processes like desorption/absorption with the environment, the reaction with enzymes of bacteria and fungi, and the influence of ultraviolet light truly indicate their importance in the physical, mechanical, and chemical properties of cellulose [9]. Cellulose is a material with unique tensile properties. In its pure form, fibers stronger than Kevlar can be tailored (cellulose is $70-137 \mathrm{GPa}$ while Kevlar is $100 \mathrm{GPa}$ ) [3]. Cellulose, wood, and lignocellulosic materials have high reactive surface of hydroxyl groups that facilitate chemical modification to achieve different surface properties which allows for proper interaction with the hydrophobic surface of the most commonly used synthetic polymers $[3,13]$. The presence of large hydroxyl groups in the cellulose polymer allows for the preparation of cellulose derivatives by applying the chemistry of alcohols [11]. Derivatization of cellulose using reactions like etherification and esterification for valueadded products like ether and ester is a subject of continuing interest because of the wide applications of these products as fibers, fillers, dialysis membranes, adhesives, explosives, thickening agents in foods, moisture-proof coatings, films, toys, cellulosic dyes, and packaging materials $[3,8,11,14]$.

New technologies have been used for the chemical and mechanical modification of cellulosic materials. Some of these techniques have been applied for the production of modified cellulosic materials for our daily and industrial needs. Cellulosic materials are generally strong, hydrophilic, biodegradable, recyclable, and insoluble in water. Typically, the purpose of the modifications is either to reinforce the original properties of cellulose or to add new functionalities in order to create a cellulosic product with specific properties. By virtue of the hydroxyl groups of cellulose and lignocellulosic polymers, they can partially or fully react with various reagents to yield derivatives with industrial and commercial potentials.

Wood is a biopolymer polymeric material considered as a very friendly and useful raw material used extensively for various construction purposes. Wood is a biopolymer with a complex structure and composed of elongated cells whose walls have complex and multilayered structures and constituting cellulose, lignin, and hemicelluloses $[9,13]$. These biopolymer makes up the bulk of the cell wall and determines the basic chemistry in wood which explains most of the physical and chemical changes observed in wood, wood-based products, and lignocellulosic materials. Wider applications of wood are restricted due to its susceptibility to certain environmental degradative agents. To improve the performance of wood/lignocellulosic materials for wider applications, the early concept introduced by H. Staudinger is applied to transform the basic functionalities (predominantly - $\mathrm{OH}$ groups in cellulose, lignin, and hemicelluloses) in order to have wood/wood-based as well as lignocellulosic products with improved properties [13]. The high moisture sensitivity of the lignocellulosic fiber causes the dimensional instability and limits the use of natural fibers as reinforcement in composite/blend materials [12]. Low interfacial properties between fiber and polymer matrix often reduce their potential as reinforcing agents due to the hydrophilic nature of fibers, which is their major drawback for being used in biocomposite, which reduces natural fiber compatibility with hydrophobic polymer matrix throughout composite fabrication $[12,15]$. The inability of wood fibers/cellulosic materials to interact well with polymer components in composite/blends systems causes poor performance of the material and necessitates the use of chemical modification to enhance the surface adhesion between components. Chemical modification is one of the methods that alter basically the structure of wood by optimizing the interface of fibers by introducing new moieties which can efficiently improve surface interlocking within the plastic matrix $[9,12]$.

Cellulose/lignocellulosic materials are made up of cellulose nanofibers that are extremely strong and have the potentials to replace nonsustainable materials such as plastics and metals. Isolation of nanodimensional cellulose from wood sources and its use in nanocomposites, biocomposite and biodegradable blends will allow the production of much lighter weight materials to replace metals and plastics in various applications [3]. Natural fibers are in general lighter than man-made fibers and tend to have mechanical properties comparable to those of glass fiber reinforced plastics when they are used as fiber composite reinforcements [6].

Wood fibers can be obtained from sawmill chips, saw-dust, wood flour/powder, cutter shavings, and wood pulp/wood residues. Wood fiber acts as more reinforcing in the composite than the wood flour which acts more as a filler [6]. There is a growing interest in natural fiber composite for industrial applications in developed countries, particularly for the production of novel materials with nanoscale dimensions that are also ecofriendly for industrial applications. This is partly due to environmental concern about manmade composite, but mostly due to their potential in cost reduction and biodegradability [6]. The modified wood fiber as reinforcing biopolymer composite has advantages such as renewability, biodegradability, durability, good mechanical, flexural, thermal, and tensile properties and a broad capacity to allow tailoring or grafting of chemical species to improve barrier properties $[3,12,13,15]$.

Because of this ability, nanotechnology represents a major opportunity for wood, wood-based, and lignocellulosic materials to improve their performance and functionality 
to develop a new generation of products, such as composite/blends and paper products, to new generations of functional nanoscale lignocellulosic materials [16]. For instance, polymer nanocomposites are produced by incorporating only a few percentages of these nanomaterials normally (1$5 \%$ cellulose) into the polymer and the improvement is vast due to their large degree of surface area. These nanomaterials are commonly referred to as, for example, nanofillers, nanoparticles, nanoscale building blocks, or nanoreinforcements. Nanocomposites have improved stiffness, strength, toughness, thermal stability, barrier properties, and flame retardancy compared to the pure polymer matrix [16]. Because of the nanometric size effect, these composites show some unique outstanding properties with respect to their conventional microcomposite counterparts.

The properties of nanocomposites materials depend not only on the properties of their individual parents, but also on their morphology and interfacial characteristics. In the particular case of a polymer reinforced with rigid nanofillers, various parameters seem to be of importance in characterizing the fillers: geometrical factors such as the shape, the size, and the aspect ratio; intrinsic mechanical characteristics such as the modulus or the flexibility; surface properties such as specific surface area and surface treatment [16]. Ketene has been used for chemical modification of wood, cellulose, and lignocellulosic materials (natural fibers) through acetylation of accessible hydroxyl groups of the natural fibers [13, 17, $18]$. This work is an extension of our previous research work carried out to investigate the effects of ketene-acetylated cellulose and wood cellulose for industrial applications and enhancement of the biodegradation of polyethylene $[3,13]$.

The procedures for the ketene-modified blends whose SEM images were being studied were obtained based on the method previously described by Azeh et al. [3, 13]. The blends were characterized using scanning electron microscopy (SEM). Consequently, kinetic studies of blends in acid, base, and distilled water were also carried out to investigate their effect on blends.

\section{Experimental Procedures}

2.1. Materials and Methods. Sodium hydroxide $(\mathrm{NaOH})$ solution $(0.5 \mathrm{M})$ and hydrochloric acid $(\mathrm{HCl})$ solution $(0.5 \mathrm{M})$ were supplied by May and Baker. Distilled water was obtained from our laboratory. All reagents used were of analytical grade. Cellulose/wood cellulose used were obtained as a gift from another research group and used without further purification. Blends used in this work were obtained from our previous research work.

2.2. Acetylation. The process that generated acetylated cellulose/wood cellulose is described elsewhere [3, 13]. One gram of wood cellulose/cellulose was pretreated with $20 \mathrm{~mL}$ of $5 \% \mathrm{NaOH}$ and stirred for $15 \mathrm{~h}$ on a magnetic stirrer (mercerization). A viscous suspension was obtained; this was transferred into the reaction flask. The iron pipe adapted as the furnace was preheated for $5 \mathrm{~min}$ (to increase heating efficiency of the apparatus), after which $40 \mathrm{~mL}$ of dry acetone was distilled. This process generated the ketene that was used to acetylate the samples. The mixture was cooled to room temperature while stirring with a magnetic stirrer. It was filtered and the residues washed until neutral with distilled water and then air dried. The filtrates had two layers and were separated using a separating funnel and stored at room temperature for further treatment. The dried residues were milled in a porcelain mortar and sieved through a $2 \mathrm{~mm}$ size nylon sieve. The fine particles were collected and stored at room temperature prior to IR and NMR analyses. Other wood cellulose acetylation products were obtained from metals (magnesium turnings, zinc filings, copper metal, and sphalerite dust) using the process previously described.

2.3. Dissolution of Polyethylene (Packaged Water Sachet) and Blending Procedures. The dissolution of high-density polyethylene (packaged water sachets) follows the method described by [19]. In brief, $1 \mathrm{~g}$ pieces of nonprinted portion was placed in a reaction flask and $30 \mathrm{~mL}$ of toluene was added. The contents were placed on a hot plate at $100^{\circ} \mathrm{C}$, and a thermometer was inserted. The sachets swelled at $60^{\circ} \mathrm{C}$ and then rapidly dissolved at $80^{\circ} \mathrm{C}$ to give a clear solution. Blending of high-density polyethylene and acetylated cellulose/wood cellulose is thus described. Into the clear solution of highdensity polyethylene sachets was introduced $0.5 \mathrm{~g}$ of each ketene-treated and untreated cellulose and wood cellulose separately while stirring for $5 \mathrm{~min}$ and then spread on clean metal plates to form a film. The thin films formed were peeled off the metal plates to afford acetylated cellulose and wood cellulose-polyethylene blends [3].

2.4. Characterization of Blends Using Scanning Electron Microscopy (SEM). Surface morphology of the blends was characterized using a microscope, Carl Zeiss Axioskop 50. connected to a Canon PC 1200 Digital Camera operating at EHT voltage of $20 \mathrm{kV}$.

2.5. Water Absorption Test. The kinetics of water absorption was studied using a water absorption test. The sample dimensions were $3 \times 20 \times 200 \mathrm{~mm}$ in diameter. Prior to the test, the samples were dried in an oven at $45^{\circ} \mathrm{C}$ for $20 \mathrm{~min}$ in order to remove any water moisture content. Then, the samples were totally immersed in distilled water, $0.5 \mathrm{M} \mathrm{HCl}$, and $0.5 \mathrm{M} \mathrm{NaOH}$ at various hour intervals. After these periods of immersion, samples were removed at fixed time intervals, wiped with filter paper to remove surface adhered water, and weighed using an analytical balance. The sorption of water, acid, and alkali by the blends at time $t$ was calculated using

$$
\frac{M_{t}-M_{o}}{M_{o}} \times 100,
$$

where $M_{t}$ is the weight of blends after $24 \mathrm{~h}$ immersion in solution while $M_{o}$ is the initial weight of blends.

\section{Results and Discussion}

3.1. A Morphological Study of Ketene-Acetylated Wood Cellulose and Cellulose Blends before and after Acetylation. Acetylation of cellulose and wood cellulose as described by 


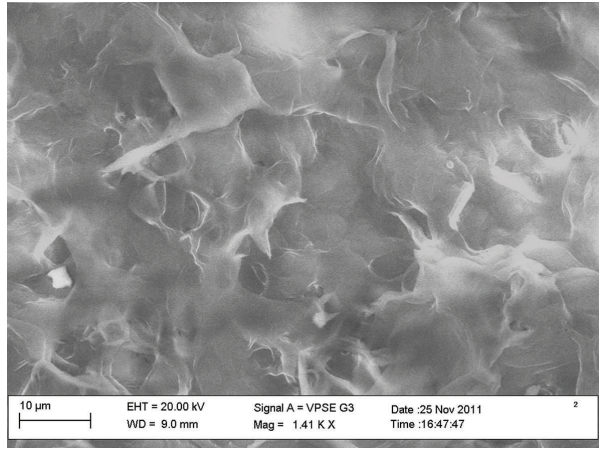

(a)

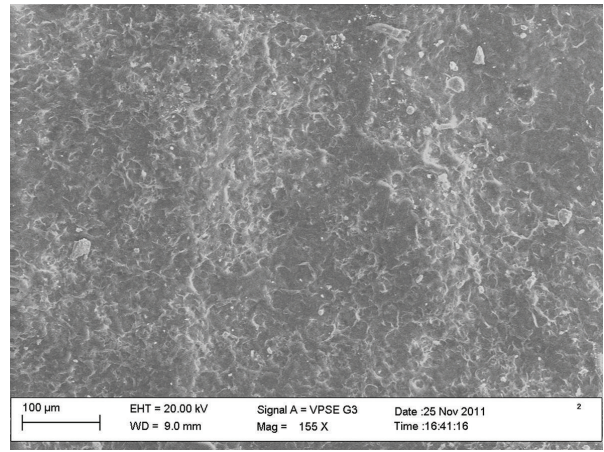

(b)

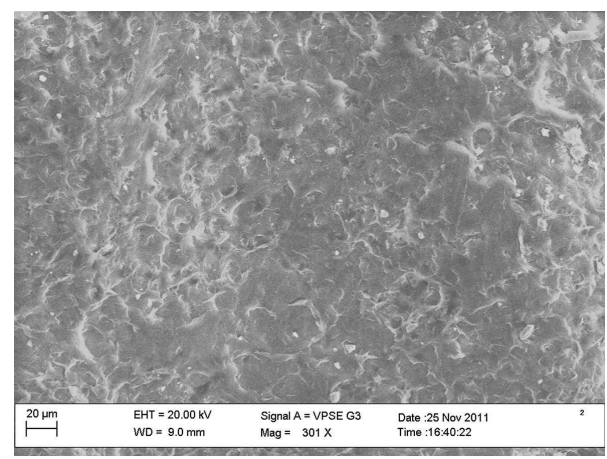

(c)

Figure 1: (a) SEM image of ketene-treated lignocellulosic fiber (wood cellulose). (b) SEM image of ketene-treated lignocellulosic fiber (wood cellulose). (c) SEM image of ketene-treated lignocellulosic fiber (wood cellulose).

Azeh et al. $[3,13]$ results in removal of hemicelluloses in wood and transformation of cellulose I $\alpha$ to cellulose II $\beta$. This treatment has resulted in the following morphological changes observed in the SEM micrographs of both treated and untreated samples. Acetylation has led to a decrease of the fiber cross-section, thereby smoothing its outer surface. That is, the transformation cellulose $\mathrm{I} \alpha$ to cellulose II $\beta$ by acetylation is irreversible at both the crystallographic and morphological level as shown in Figures 1(a) and 1(c).

The scanning electron microscopy (SEM) images showed the crystalline pattern of cellulose and the interfacial interactions of acetylated samples with polyethylene, which explains the dispersibility of treated cellulose attributed to acetyl moieties on cellulose surface as they interact well with polyethylene. The absence of cavities and pulled-out fibers confirmed that the interfacial bonding between acetylated cellulose, wood cellulose, and the polymer (polyethylene) matrix was good and strong. Because of the transformation of hydrophilic surfaces of wood cellulose and cellulose to hydrophobic surfaces through acetylation, the polymer blends showed better interfacial adhesion between the fibers and the polymer matrix and these surfaces were smooth. As a result, there were no fracture surfaces and pull-out fibers. The crystalline surface of blends formed from treated samples is indicative of the removal of the amorphous regions of cellulose in these samples by mercerization and acetylation $[14,20]$. Figures 1 (a) and 2(b) illustrate the scanning electron micrograph of polyethylene blends reinforced with ketene-acetylated wood cellulose and cellulose at $0.5 \mathrm{~g}$ cellulose $/ 1.0 \mathrm{~g}$ polyethylene ratio in toluene. Figures 1(a) and 2(b) showed that the acetylation of fiber surfaces has changed the blend surfaces by reducing disordered regions in the fibers. A comparison of acetylated cellulose fiber blend surface with that of the blend before treatment showed that surface roughness of blends after treatment is lower than that of untreated blends. A high decrease in surface roughness of blends in acetylated samples is a direct evidence of interfacial compatibility of fiber and matrix surfaces $[15,20]$. An increase in the degree of crystallinity with respect to the degree of acetylation which is due to the removal of lignin and extractible and small weight percent gains (WPGs) have been reported to increase the crystallinity of cellulose [12]. In this work, ketene which is known to give small weight percent gains was used for the acetylation of wood cellulose and cellulose, and this effect can be seen in the morphology of the blends being studied [21].

Figures 3(a) and 3(c) illustrate the SEM images of blends reinforced with untreated wood cellulose and cellulose samples. The blends showed numerous cavities and pull-out fibers can be seen and they were also not smooth. There were more observable cellulose microbundles, and also the localized bunch of fibers and patches can be seen which are indicative of the poor dispersion of untreated cellulose within the polyethylene matrix. Thus, the surface of the blends reinforced with untreated cellulose appeared to be dominated by pull-out amorphous fiber surfaces. Similar 


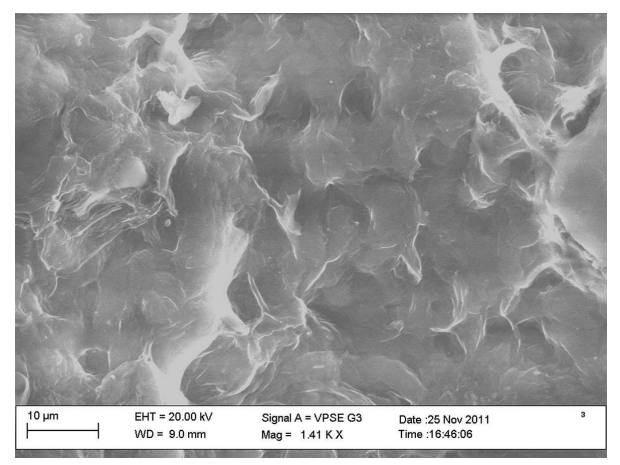

(a)

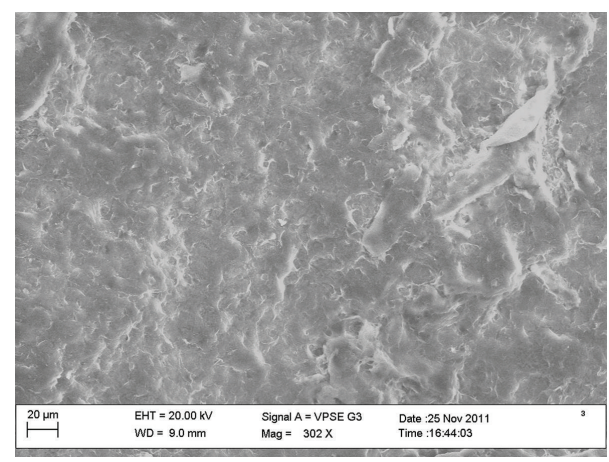

(b)

FIGURE 2: (a) SEM image of ketene-treated cellulose blend. (b) SEM image of ketene-treated cellulose blend.

surfaces have been reported $[15,18]$. There were also no even distribution of fiber within the polymer matrix and the blend surfaces were rough indicating the presence of disordered cellulose regions. It is also observed that the cellulose particles in the fiber form were oriented randomly, and as the fiber-matrix interfacial adhesion was poor, the blends showed some gaps and signs of a pull-out tendency. These is attributed to the biofiber, hydrophilic nature, which reduces their compatibility with hydrophobic polymer matrix throughout composite/blend fabrication [15]. A comparison of acetylated wood cellulose and cellulose blends surface with that of the blends before treatment showed that surface roughness of blends after treatment is lower than that of untreated blends. The surface of the treated blends displayed the crystallinity of treated cellulose as well as wood cellulose and their dispersibility in the polymer matrix.

\subsection{Effect of Acetylation on Water Absorption of Ketene-Acety-} lated Wood Cellulose and Cellulose Blends. The use of fibers as reinforcing material and fiber loading on synthetic polymers has effect on water absorption of biocomposites/blends [15]. Since biofibers are hydrophilic in nature due to the presence of numerous hydroxyl functionality, acetals, and ether linkages in cellulose structure, the free hydroxyl groups in cellulose, hemicelluloses, and lignin interact with water molecules by hydrogen bonding. Therefore, as expected, the addition of cellulosic material to the synthetic polymer to form biocomposites/blends increased the water absorption of the biocomposites/blends. Because polyethylene (HDPE)

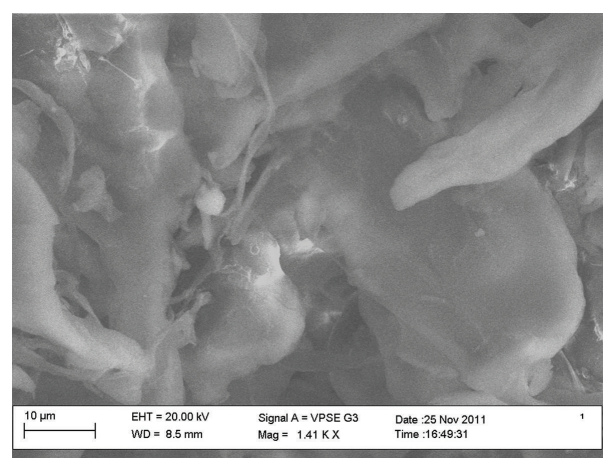

(a)

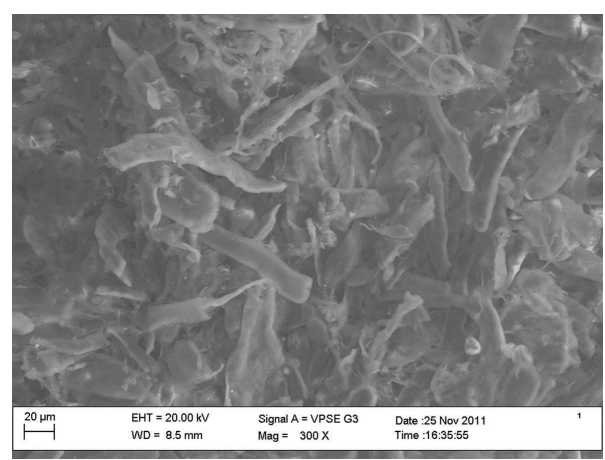

(b)

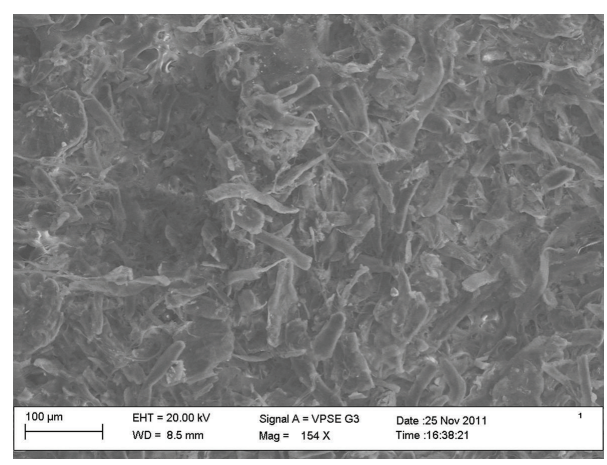

(c)

FIGURE 3: (a) Untreated cellulose polyethylene blends. (b) Untreated cellulose polyethylene blend. (c) Untreated cellulose polyethylene blend.

is hydrophobic and the wood cellulose and cellulose are hydrophilic, the absorption of water is a function of fiber alone. As the fiber loading increased, the cellulose content increased, which in turn resulted in the absorption of more water. It has been reported that the hydrophilicity of the fibers can be reduced by a suitable chemical treatment [20]. Table 1 illustrates the percent uptake of the solvent by both treated and untreated cellulose and wood cellulose samples obtained after $24 \mathrm{~h}$ immersion in distilled water, $0.5 \mathrm{M} \mathrm{NaOH}$, and $0.5 \mathrm{M} \mathrm{HCl}$ solutions, respectively.

However, acetylation is known to reduce the hygroscopicity of cellulosic materials, and since wood cellulose and cellulose have been acetylated, it is expected that the blends reinforced with acetylated cellulosic materials will absorb less water molecules as compared to the untreated samples (Table 1). Accessible hydroxyl groups in the fibers 
TABle 1: Percent solvent uptake of treated and untreated blend samples.

\begin{tabular}{lccc}
\hline & $\begin{array}{c}\text { Treated cellulose } \\
\text { blend }\end{array}$ & $\begin{array}{c}\text { Treated wood } \\
\text { cellulose blend }\end{array}$ & $\begin{array}{c}\text { Untreated } \\
\text { cellulose blend }\end{array}$ \\
\hline $\mathrm{NaOH}(0.5 \mathrm{M})$ & 14.29 & 14.29 & 71.43 \\
$\mathrm{HCl}(0.5 \mathrm{M})$ & 42.86 & 42.86 & 85.71 \\
$\mathrm{H}_{2} \mathrm{O}$ & 12.86 & 12.86 & 57.14 \\
\hline
\end{tabular}

have been converted to acetyl moieties through acetylation. The highest percent solvent uptake was found with blends reinforced with untreated cellulose, which was attributed to the hydrophilic (presence of polar groups like hydroxyl, acetals, and ether linkages) nature of cellulose fibers in the cellulose structure. According to George et al. [20] the hydrophilicity of cellulose fibers can be reduced by a suitable chemical treatment. The results obtained in this work (Table 1) agree with his findings. The treated cellulose blends showed a lower degree of solvent absorption when compared to the untreated cellulose blends. As a result of the chemical treatment, the ketene reacted with the hydroxyl group of the cellulose by a mechanism well established to form acetylated cellulose and wood cellulose, respectively. Blending of the like surfaces gave rise to covalent bond formation between the hydrophobic acetylated cellulose and the hydrophobic polymer matrix and thus established a good fiber/matrix bonding interaction. Consequently, the chance of having hydroxyl groups coming into contact with water molecules was reduced as can be seen from the absorption test.

\section{Conclusion}

In this work, we have been able to further prove that acetylation of cellulose and wood cellulose using ketene was successful [13]. Kinetic studies showed that the treated blends showed a reduction in hygroscopicity implying that the blends are fit for use as biodegradable packaging materials. The uptake of water, acid, and alkali solutions was due to the hydrophilicity of cellulose. Morphological studies using SEM showed that fiber chemical treatment using ketene at $0.5 \mathrm{~g} / 1.0 \mathrm{~g}$ fiber/matrix loading also improved the fibermatrix surface interaction, which led to better incorporation of the fiber with the matrix.

\section{References}

[1] J. Zhang, T. J. Elder, Y. Pu, and A. J. Ragauskas, "Facile synthesis of spherical cellulose nanoparticles," Carbohydrate Polymers, vol. 69, no. 3, pp. 607-611, 2007.

[2] H. B. T. Abdulaziz, Reactive extraction of sugars from oil palm fruit bunch hydrolysate using naphthalene-2-boronic acid [M.S. thesis], Graduate Faculty Universiti of Sains Malaysia, 2007.

[3] A. Yakubu, T. M. Umar, and S. S. D. Mohammed, "Chemical modification of microcrystalline cellulose: improvement of barrier surface properties to enhance surface interactions with some synthetic polymers for biodegradable packaging material processing and applications in textile, food and pharmaceutical industry," Advances in Applied Science Research, vol. 2, no. 6, pp. 532-540, 2011.
[4] G. Rodionova, M. Lenes, Ø. Eriksen, and Ø. Gregersen, "Surface chemical modification of microfibrillated cellulose: improvement of barrier properties for packaging applications," Cellulose, vol. 18, no. 1, pp. 127-134, 2011.

[5] R. J. Moon, A. Martini, J. Nairn, J. Simonsen, and J. Youngblood, "Cellulose nanomaterials review: structure, properties and nanocomposites," Chemical Society Reviews, vol. 40, no. 7, pp. 3941-3994, 2011.

[6] M. Sercer, P. Raos, and M. Rujnic-Sokele, Processing of woodthermoplastic composites, http://www.jobwerks.com/news/ Archives/iwpc.pdf.

[7] A. Biswas, B. C. Saha, J. W. Lawton, R. L. Shogren, and J. L. Willett, "Process for obtaining cellulose acetate from agricultural by-products," Carbohydrate Polymers, vol. 64, no. 1, pp. 134-137, 2006.

[8] G. A. Olatunji, "The eighty-eight inaugural lecture," in Journey to the Promised Land: The Travails of an Organic Chemist, p. 17, Department of Chemistry, Faculty of Science, University of Ilorin, Ilorin, Nigeria, 2009.

[9] B. Mohebby, "Application of ATR infrared spectroscopy in wood acetylation," Journal of Agricultural Science and Technology, vol. 10, no. 3, pp. 253-259, 2008.

[10] L. M. Ilharco, A. R. Garcia, J. Lopes da Silva, and L. F. Vieira Ferreira, "Infrared approach to the study of adsorption on cellulose: influence of cellulose crystallinity on the adsorption of benzophenone," Langmuir, vol. 13, no. 15, pp. 4126-4132, 1997.

[11] I. Filpponen, The synthetic strategies for unique properties in cellulose nanocrystals materials [Ph.D. thesis of Philosophy], Graduate Faculty of North Carolina State University, Wood \& Paper Science, Raleigh, NC, USA, 2009.

[12] A. K. Bledzki, A. A. Mamun, M. Lucka-Gabor, and V. S. Gutowski, "The effects of acetylation on properties of flax fibre and its polypropylene composites," Express Polymer Letters, vol. 2, no. 6, pp. 413-422, 2008.

[13] A. Yakubu, G. A. Olatunji, O. Sunday, and A. Olubunmi, "Ketene acetylated wood cellulose for industrial applications in wood-base and polymer industry," Journal of Environmental Science and Technology, vol. 5, no. 3, pp. 168-176, 2012.

[14] G. T. Ciacco, D. L. Morgado, E. Frollini, S. Possidonio, and O. A. El Seoud, "Some aspects of acetylation of untreated and mercerized sisal cellulose," Journal of the Brazilian Chemical Society, vol. 21, no. 1, pp. 71-77, 2010.

[15] S. Samira, A. I. Nor, A. Sanaz, W. Y. Wan Md Zin, and A. R. M. Zaki, "Effects of fibre esterification on fundamental properties of oil palm empty fruit bunch fibre/poly (butylenes adipate-co-terephthalate) biocomposites," International Journal of Molecular Sciences, vol. 13, no. 2, pp. 1327-1346, 2012.

[16] S. Kamel, "Nanotechnology and its applications in lignocellulosic composites, a mini review," Express Polymer Letters, vol. 1, no. 9, pp. 546-575, 2007.

[17] R. M. Rowell, R. H. S. Wang, and J. A. Hyatt, "Flakeboards made from Aspen and Southern Pine Wood flakes Reacted with Ketene," Journal of Wood Chemistry and Technology, vol. 6, no. 3, pp. 449-471, 1986.

[18] A. G. Supri and B. Y. Lim, "Effect of treated and untreated filler loading on the mechanical, morphological, and water absorption properties of water hyacinth fibers-low density polyethylene composites," Journal of Physical Science, vol. 20, no. 2, pp. 85-96, 2009.

[19] S. A. Abdulkareem and B. Garba, "Novel application of polymer dissolution technique," Nigerian Journal of Pure and Applied Sciences, vol. 20, pp. 1799-1485, 2005. 
[20] J. George, S. S. Bhagawan, and S. Thomas, "Effects of environment on the properties of low-density polyethylene composites reinforced with pineapple-leaf fibre," Composites Science and Technology, vol. 58, no. 9, pp. 1471-1485, 1998.

[21] V. Tserki, N. E. Zafeiropoulos, F. Simon, and C. Panayiotou, "A study of the effect of acetylation and propionylation surface treatments on natural fibres," Composites A, vol. 36, no. 8, pp. 1110-1118, 2005. 


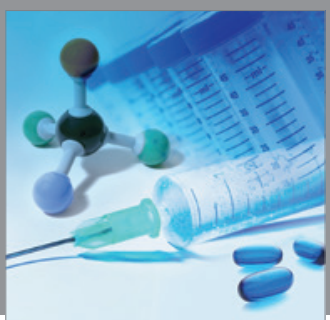

International Journal of

Medicinal Chemistry

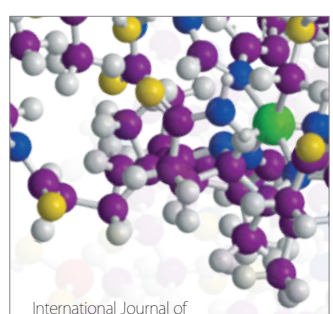

Carbohydrate Chemistry

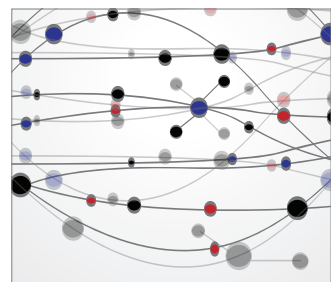

The Scientific World Journal
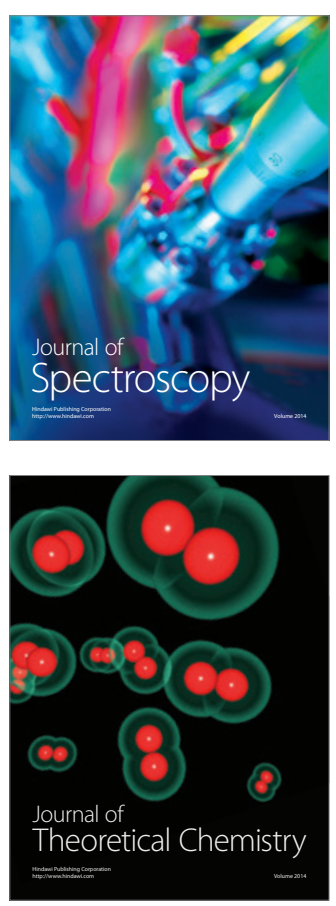
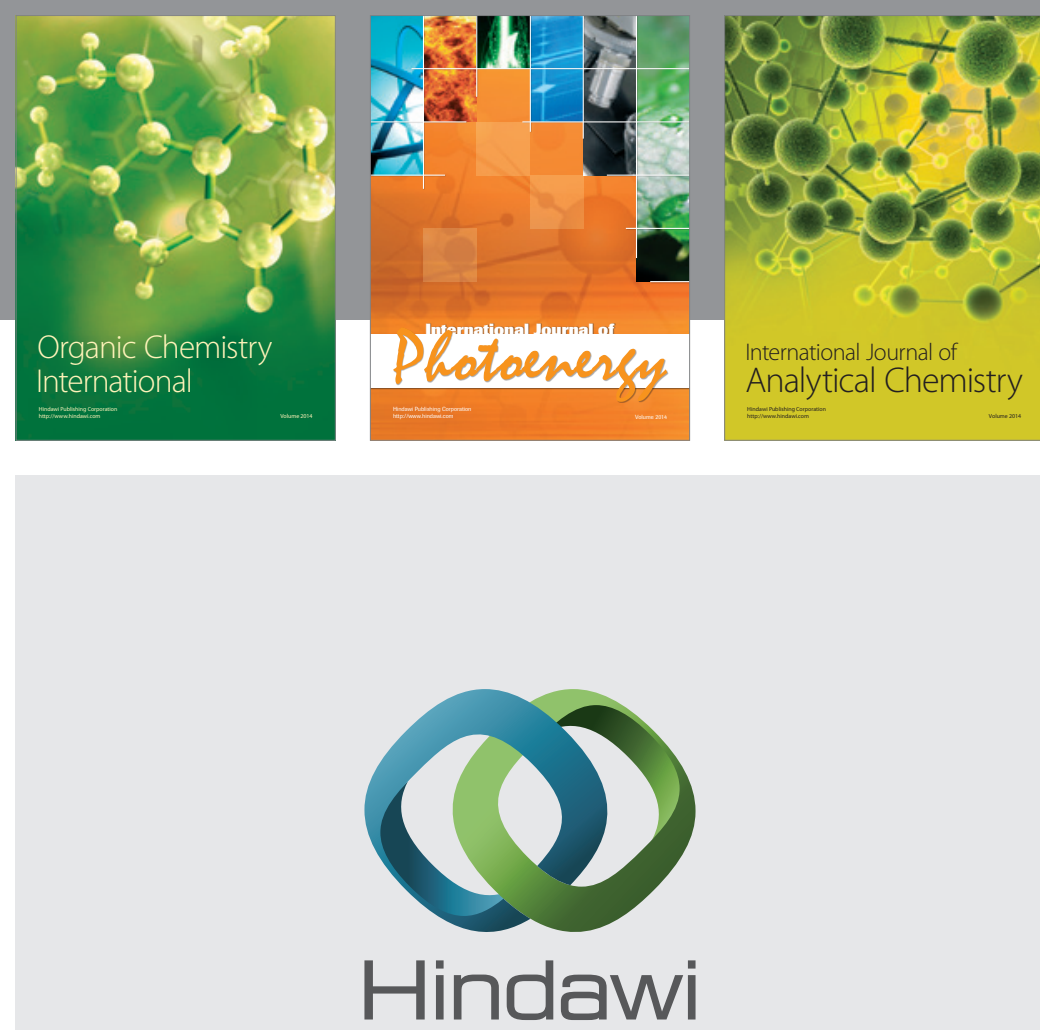

Submit your manuscripts at

http://www.hindawi.com
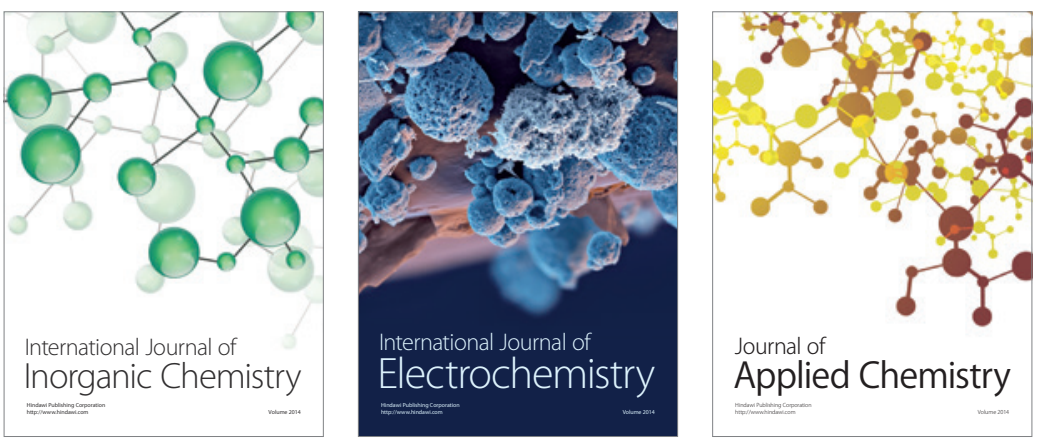

Journal of

Applied Chemistry
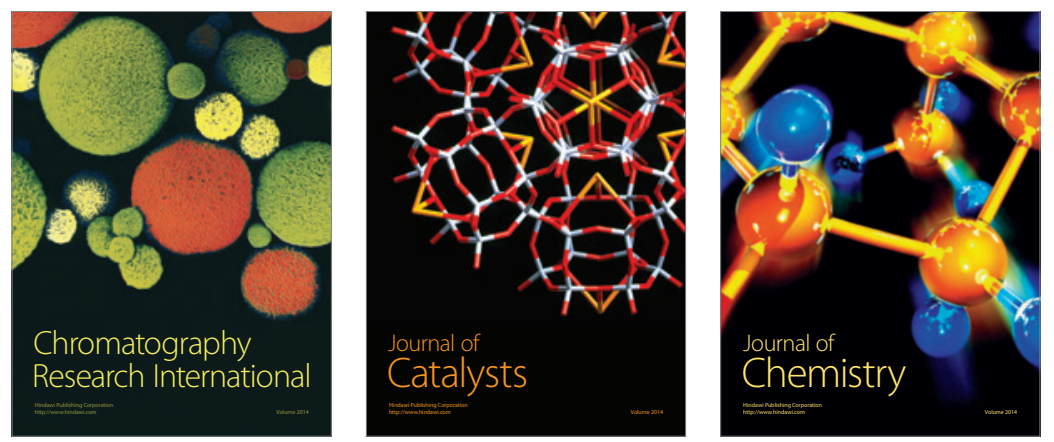
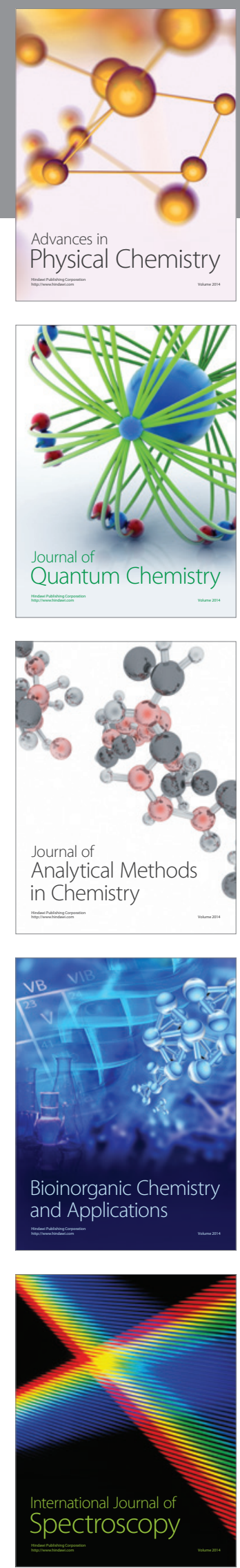